\title{
The use of statins in people at risk of developing diabetes mellitus: Evidence and guidance for clinical practice
}

\author{
Naveed A. Sattar ${ }^{a}$,*, Henry Ginsberg ${ }^{\mathrm{b}, 1}$, Kausik Ray ${ }^{\mathrm{c}}$, M. John Chapman ${ }^{\mathrm{d}}$, Marcello Arca ${ }^{\mathrm{e}}$, \\ Maurizio Averna ${ }^{\mathrm{f}}$, D. John Betteridge ${ }^{\mathrm{g}}$, Deepak Bhatnagar ${ }^{\mathrm{h}}$, Elena Bilianou ${ }^{\mathrm{i}}$, \\ Rafael Carmena ${ }^{\mathrm{j}}$, Richard Češka ${ }^{\mathrm{k}}$, Alberto Corsini ${ }^{1}$, Raimund Erbel ${ }^{\mathrm{m}}$, Paul D. Flynn ${ }^{\mathrm{n}}$, \\ Xavier Garcia-Moll ${ }^{\circ}$, Janusz Gumprecht ${ }^{\mathrm{p}}$, Shun Ishibashi ${ }^{\mathrm{q}}$, Selim Jambart ${ }^{\mathrm{r}}$, \\ John J.P. Kastelein ${ }^{\mathrm{s}}$, Vincent Maher ${ }^{\mathrm{t}}$, Pedro Marques da Silva ${ }^{\mathrm{u}}$, Luis Masana ${ }^{\mathrm{v}}$, \\ Masato Odawara ${ }^{\mathrm{w}}$, Terje R. Pedersen ${ }^{\mathrm{x}}$, Carlo Maria Rotella ${ }^{\mathrm{y}}$, Ibrahim Salti ${ }^{\mathrm{y}}$, \\ Tamio Teramoto ${ }^{\text {aa }}$, Lale Tokgozoglu ${ }^{\text {ab }}$, Peter P. Toth ${ }^{\text {ac }}$, Paul Valensi ${ }^{\text {ad }}$, Bruno Vergès ${ }^{\text {ae }}$
}

${ }^{a}$ Institute of Cardiovascular \& Medical Sciences, BHF Glasgow Cardiovascular Research Centre, University Of Glasgow, 126 University Place, Glasgow G12 8TA, UK

${ }^{\mathrm{b}}$ Irving Institute for Clinical and Translational Research, PH 10-305, Columbia University College of Physicians and Surgeons, 630 West 168th Street, New York, NY 10032, USA

${ }^{\mathrm{c}}$ Cardiovascular Sciences Research Centre, St Georges University of London, Cranmer Terrace, London SW17 ORE, UK

${ }^{\mathrm{d}}$ Dyslipidemia and Atherosclerosis Research Unit, INSERM UMR-S939, Pitie-Salpetriere University Hospital, 75651 Paris, France

${ }^{\mathrm{e}}$ Department of Internal Medicine and Allied Sciences, Sapienza University of Rome, Viale del Policlinico 155, 00161 Rome, Italy

${ }_{\mathrm{f}}^{\mathrm{f}}$ Dept. of Internal Medicine and Medical Specialties, School of Medicine, University of Palermo, Italy

${ }^{\mathrm{g}}$ University College London, Middlesex Hospital, London, UK

${ }^{\mathrm{h}}$ Diabetes Centre, The Royal Oldham Hospital, Rochdale Road, Oldham, UK

${ }^{\mathrm{i}}$ Lipid Clinic, Cardiology Department, Tzanio Hospital, Pireas, Greece

${ }^{\mathrm{j}}$ Department of Medicine, University of Valencia, Spain

${ }^{\mathrm{k}}$ Center of Preventive Cardiology, IIIrd Dept. Int. Med. Charles University and University General Hospital, Prague, Czech Republic

${ }^{1}$ Dipartimento di Scienze Farmacologiche e Biomolecolari, Università degli Studi di Milano, Milan, Italy

${ }^{\mathrm{m}}$ Department of Cardiology, West German Heart Centre, University of Essen, Germany

${ }^{\mathrm{n}}$ The Lipid Clinic, Box 153, Addenbrooke's Hospital, Cambridge CBO 2QQ, UK

${ }^{\circ}$ Unitat Hospitalització, Servei de Cardiologia, Hospital de la Santa Creu i Sant Pau, Spain

${ }^{\mathrm{p}}$ Katedra i Klinika Chorób Wewętrznych, Diabetologii i Nefrologii, Ślaski Uniwersytet Medyczny, Katowice, Poland

${ }^{\mathrm{q}}$ Department of Internal Medicine, Division of Endocrinology and Metabolism, Jichi Medical University, 3311-1, Yakushiji Shimotsuke-shi, Tochigi 3290498, Japan

${ }^{\mathrm{r}}$ St-Joseph University Faculty of Medicine, and Head, Endocrinology and Metabolism Division, Hotel-Dieu de France Hospital, Beirut, Lebanon

${ }^{\mathrm{s}}$ Academic Medical Center/University of Amsterdam, Dept. of Vascular Medicine, F4-159.2, Meibergdreef 9, 1105 AZ Amsterdam, The Netherlands ${ }^{\mathrm{t}}$ Department of Cardiology, Tallaght Hospital, Dublin, Ireland

u'Arterial Investigation Unit, Medicine IV, Santa Marta's Hospital, CHLC, Lisboa, Portugal

${ }^{\vee}$ Unitat de Recerca en Lipids i Arteriosclerosi, IISPV, CIBERDEM, Universitat Rovira i Virgili, Sant Llorenç, 21, 43201 Reus, Spain

${ }^{\mathrm{w}}$ Division of Diabetology, Endocrinology and Metabolism, The Third Department of Internal Medicine, Tokyo Medical University, 6-7-1, Nisi-shinjuku, Shinjuku-ku, Tokyo 160-0023, Japan

\footnotetext{
* Corresponding author. Tel.: +44 141330 3419; fax: +44 1413306972.

E-mail addresses: naveed.sattar@glasgow.ac.uk (N.A. Sattar),hng1@columbia.edu (H. Ginsberg), kray@sgul.ac.uke (K. Ray), john.chapman@upmc.fr (M.J. Chapman), marcelloarca@libero.it (M. Arca), maurizio.averna@unipa.it (M. Averna),rmhajbe@ucl.ac.uk (D.J. Betteridge), deepak.bhatnagar@ manchester.ac.uk (D. Bhatnagar), elenib1@otenet.gr (E. Bilianou), Rafael.Carmena@uv.es (R. Carmena), richard.ceska@vfn.cz (R. Češka), alberto. corsini@unimi.it (A. Corsini), Raimund.Erbel@uk-essen.de (R. Erbel), pdf21@cam.ac.uk (P.D. Flynn), XGarcia-Moll@santpau.cat (X. Garcia-Moll), jgumprecht@sum.edu.pl (J. Gumprecht), ishibash@jichi.ac.jp (S. Ishibashi), sjambart@dm.net.lb (S. Jambart), j.j.kastelein@amc.uva.nl (J.J.P. Kastelein), vmaher@gmail.com (V. Maher), pedro.silva@hsmarta.min-saude.pt (P. Marques da Silva), luis.masana@urv.cat (L. Masana), odawara@tokyo-med.ac.jp (M. Odawara), t.r.pedersen@medisin.uio.no (T.R. Pedersen), c.rotella@dfc.unifi.it (C.M. Rotella), isalti@aub.edu.lb (I. Salti), ttera@med.teikyo-u.ac.jp (T. Teramoto), lalet@hacettepe.edu.tr (L. Tokgozoglu), peter.toth@cghmc.com (P.P. Toth), paul.valensi@jvr.aphp.fr (P. Valensi), bruno.verges@chu-dijon. fr (B. Vergès).

${ }^{1}$ Tel.: +1 2123059562 .
} 


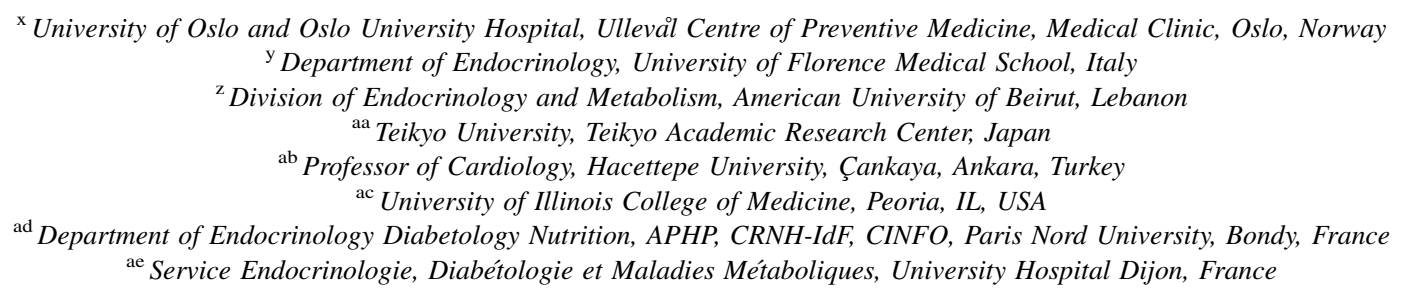

\begin{abstract}
Reducing low-density lipoprotein cholesterol (LDL-C) levels using statins is associated with significant reductions in cardiovascular (CV) events in a wide range of patient populations. Although statins are generally considered to be safe, recent studies suggest they are associated with an increased risk of developing Type 2 diabetes (T2D). This led the US Food and Drug Administration (FDA) to change their labelling requirements for statins to include a warning about the possibility of increased blood sugar and HbA1c levels and the European Medicines Agency (EMA) to issue guidance on a small increased risk of T2D with the statin class. This review examines the evidence leading to these claims and provides practical guidance for primary care physicians on the use of statins in people with or at risk of developing T2D. Overall, evidence suggests that the benefits of statins for the reduction of CV risk far outweigh the risk of developing T2D, especially in individuals with higher CV risk. To reduce the risk of developing T2D, physicians should assess all patients for T2D risk prior to starting statin therapy, educate patients about their risks, and encourage risk-reduction through lifestyle changes. Whether some statins are more diabetogenic than others requires further study. Statin-treated patients at high risk of developing T2D should regularly be monitored for changes in blood glucose or HbA1c levels, and the risk of conversion from pre-diabetes to T2D should be reduced by intensifying lifestyle changes. Should a patient develop T2D during statin treatment, physicians should continue with statin therapy and manage T2D in accordance with relevant national guidelines.
\end{abstract}

(C) 2014 Published by Elsevier Ireland Ltd.

Keywords: Statins; Diabetes; Diabetogenicity; T2D; Cardiovascular; CVD

\section{Introduction}

Cardiovascular disease (CVD) accounts for approximately $50 \%$ of all deaths in Europe and, as the primary cause of disease burden, is estimated to cost the European economy Euros 196 billion, annually [1]. Major modifiable risk factors for CVDs include tobacco use, dyslipidaemia, hypertension, Type 2 diabetes mellitus (T2D), poor diet, physical inactivity and obesity [2-4]. Because these risk factors tend to co-exist with a multiplicative, rather than additive, effect on CV risk [5-7], it is important to assess and treat the individual patient's overall $\mathrm{CV}$ risk $[2,3]$. Moreover, since T2D and CVD have some overlapping risk factors and often co-exist, the 2013 European Society of Cardiology (ESC)/European Association for the Study of Diabetes (EASD) Guidelines on Diabetes, Pre-diabetes, and Cardiovascular Diseases suggest that all patients with CVD or CV risk factors should routinely be screened for T2D [8] using either glycated haemoglobin (HbAlc) or fasting plasma glucose (FPG) as markers. Diabetes risk scores should be used in advance of deciding which patients would benefit from glycaemia testing.

Current best practice for reducing CV risk includes lifestyle changes such as improved diet, weight loss, regular physical activity, and (when applicable) smoking cessation, together with pharmacotherapy to improve lipid profile and blood pressure [2,8-11,18]. Although the management of $\mathrm{CV}$ risk factors has improved over recent years [12], the clinical impact of these gains will potentially be attenuated by the increasing pandemics of obesity and T2D as atherosclerotic disease is accelerated in T2D [12-14]. Currently, the worldwide incidence of T2D is predicted to increase from 342 million in 2011 to 534 million by 2030 [15] and the number of $\mathrm{CV}$ deaths is predicted to increase from 17.1 million in 2004 to 23.6 million in 2030 [16]. The fact that both CVD and T2D are strongly related to a western lifestyle (i.e. smoking, insufficient exercise, and a high-fat, highrefined sugar diet comprising a large proportion of processed food) suggests that greater efforts are needed at every level (including Governmental policies targeted at the food industry) to encourage lifestyle changes. A tool kit providing practical advice for healthcare professionals has recently been developed to aid this process $[8,17]$.

\section{Statins are safe and effective for the reduction of $\mathrm{CV}$ risk in a wide range of patients}

Dyslipidaemia - characterised by increased concentrations of the pro-atherogenic apolipoprotein-B containing lipoproteins (low-density lipoproteins [LDLs], very-low 
density lipoproteins [VLDLs], chylomicrons [CMs] and VLDL-/CM-remnants) and reduced levels of potentially antiatherogenic apolipoprotein-A-I containing high-density lipoproteins [HDLs] - accounts for a significant proportion of the population-attributable risk for cardiovascular disease [7]. Numerous clinical trials have demonstrated the benefits of lowering LDL-C with statins for the reduction of CV risk in a wide range of populations [10,19-24]. For example, the Cholesterol Treatment Trialist's Collaboration (CTTC) meta-analyses showed that each $1 \mathrm{mmol} / \mathrm{L}$ $(38.6 \mathrm{mg} / \mathrm{dL})$ reduction in LDL-C is associated with a significant $21 \%$ proportional reduction in major vascular events in people with $(0.79,0.72-0.86 ; P<0.0001)$ and without T2D $(0.79,0.76-0.82 ; P<0.0001)$ [21]. More recent studies have demonstrated that statins are similarly beneficial for the primary and secondary prevention of CVD $[10,20,24]$ and that the relative risk reduction is similar even in patients with very low absolute CV risk [22]. These results are partially explained by intra-vascular ultrasound (IVUS) studies showing that intensive LDL-C lowering using statins can significantly slow, and even reverse, the progression of atherosclerotic plaques in people with coronary heart disease (CHD) [25,26]. Consequently, statins remain the first-line lipid-lowering strategy for the vast majority of people with $\mathrm{CV}$ risk, including those with T2D.

Statins are associated with an excellent safety and tolerability profile [22,27-32]. Although observational studies had raised concerns about a possible link between long-term statin use and the increased incidence of non-CV morbidity or mortality (e.g. cancer, memory loss and psychiatric disorders), such claims have been fully refuted by randomised, placebo-controlled clinical trials [22,30-32]. However, no drugs are completely risk-free and a number of dose-dependent adverse events (AEs) have been reported for statins, the most common of which include elevations in liver enzymes, myalgia, and (rarely) rhabdomyolysis [27-29,33]. Reassuringly, a meta-analysis of 72 trials involving 159,458 patients showed no significant difference between statins and placebo on the incidence of rhabdomyolysis $(0.25 \%$ versus $0.25 \%$; OR 1.05 , 95\% CI 0.84-1.31) or elevated creatine kinase level (OR $1.09,95 \%$ CI $0.85-1.41$ ) [27]. However, of the currently used statins, the $80 \mathrm{mg}$ dose of simvastatin was significantly associated with an increased incidence of myopathy in both the Aggrastat-Zocor (A-Z) study and the Study of the Effectiveness of Additional Reductions in Cholesterol and Homocysteine (SEARCH) study [34]. However, statinrelated AEs are usually resolved by drug discontinuation and/or by reducing the statin dose and, in general, the benefits of statin use far outweigh the possible risks, even in primary prevention patients with very low CV risk [22,24].

A number of studies have raised the possibility that statins are associated with an increased relative risk of developing T2D [35,36,38-48], although the absolute risk remains small and may vary by baseline risk of developing T2D. This is a potential concern because long-term T2D is associated with, on average, a 2-fold increased risk of CV morbidity and mortality [49-51] and an increased incidence of death from non-CV related disorders, including several cancers, infectious diseases, external causes, intentional self-harm, and degenerative disorders [51]. Of course, risk levels vary depending on the duration of T2D and the presence of comorbidities, such as chronic kidney disease. Nevertheless, approximately $10 \%$ of all CV deaths in the developed world over the past 10 years were attributed to T2D [50]. In 2012, the US Food and Drug Administration (FDA) changed their labelling requirements for statins to include a warning about the possibility of increased blood sugar and HbAlc levels [52]. This sparked an ongoing debate about the risks and implications of developing T2D with statin use that led the American Heart Association (AHA)/American College of Cardiology (ACC) to incorporate new advice in their 2013 cholesterol treatment guidelines [11]. The aim of this paper is to examine the evidence leading to these concerns and to provide practical guidance for primary care physicians on the use of statins in people with, or at risk of developing, T2D.

\section{Guidelines for the management of dyslipidaemia and CVD}

International guidelines for the management of dyslipidaemia and CVD recommend reducing LDL-C to specific targets or by specific statin regimes depending on a patient's overall level of CV risk [2-4,8,11,53-55]. Patients with established T2D are either classified as high risk or, for those with $\mathrm{T} 2 \mathrm{D}$ and at least one other $\mathrm{CV}$ risk factor or target organ damage, very high risk. For patients without T2D, CV risk stratification is carried out using the European Systematic Coronary Risk Evaluation (SCORE) charts in Europe, the New Pooled Cohort Risk Equation (ASCVD) in the USA and Framingham Risk Score (FRS) charts in Canada [2,3,11,53-55], although some countries (e.g. UK) suggest statins for all patients with type 2 diabetes above certain age. The identification of low HDL-C levels as a residual risk factor for CVD [56] has led to the integration of HDL-C values into recent charts $[2,3,8,9]$. This is particularly important for people with obesity, a sedentary lifestyle, pre-diabetes or undiagnosed T2D, who typically have low levels of HDL-C in addition to elevated levels of triglyceride and remnant particles.

Most guidelines suggest lowering LDL-C to $\leq 2.5 \mathrm{mmol} /$ $\mathrm{L}(100 \mathrm{mg} / \mathrm{dL})$ in patients with high $\mathrm{CV}$ risk (T2D or SCORE 5-9\% or marked elevations in single risk factors or FRS $10-19 \%)$ and to $\leq 1.8 \mathrm{mmol} / \mathrm{L}(70-80 \mathrm{mg} / \mathrm{dL})$ or $\mathrm{a} \geq 50 \%$ reduction in LDL-C in those with very high $\mathrm{CV}$ risk (T2D and other CV risk factors or SCORE $\geq 10 \%$ or ASCVD $\geq 7.5 \%$ or FRS $\geq 20 \%$ (which may be revised down shortly to $10 \%)$ or established CVD) $[2-4,8,9,11,15]$. The recommended first-line treatment for the majority of patients with raised LDL-C is lifestyle modification to include a Mediterranean-type diet, regular exercise, smoking cessation, and weight loss $[2-4,8,9,11,15,17,53,55,57]$. In 
addition, statins should be prescribed for all high- to veryhigh risk patients that fail to achieve their recommended LDL-C target using non-pharmacological interventions $[2-4,8,9,11,15,53,55,57]$ and, according to the $2013 \mathrm{ESC} /$ EASD Guidelines for Diabetes, Pre-diabetes and CVDs, for all patients with T2D and high CV risk, irrespective of their baseline LDL-C level [8]. Although the recent guidelines from the AHA/ACC recommended high- and moderateintensity statin therapy rather than LDL-C targets, patients with T2D and either CVD or other risk factors were among those targeted for intensive LDL-C lowering [11].

\section{Guidelines for the diagnosis, prevention and treatment of T2D}

\subsection{T2D diagnosis}

The development of T2D is a gradual process that is typically associated with a cluster of modifiable risk factors, including atherogenic dyslipidaemia, raised blood pressure, obesity, smoking and/or a sedentary lifestyle, all of which increase the risk of CVD. Thus among those with impaired glucose tolerance (IGT) and/or impaired fasting glucose (IFG) (pre-diabetes), the risk of incident CVD may be elevated due to the presence of the associated risk factors. Some, but not all, patients with pre-diabetes go on to develop T2D. Although T2D typically occurs after middle age, the increasing incidence of childhood obesity has resulted in a trend towards a younger age of onset. Other non-modifiable risk factors for T2D include a family history of T2D, male gender, and Asian or other non-white ethnicity [8].

Recommendations for the diagnosis of T2D have become more consistent in recent years and now include $\mathrm{HbAlc}$ levels $\geq 6.5 \%$ ( $48 \mathrm{mmol} / \mathrm{L})$ or $\mathrm{FPG} \geq 7.0 \mathrm{mmol} / \mathrm{L}(126 \mathrm{mg} /$ $\mathrm{dL})$ or 2 -h oral glucose tolerance testing (OGTT) $\geq 11.1 \mathrm{mmol} / \mathrm{L}(200 \mathrm{mg} / \mathrm{dL})[4,8,15,58,59]$. HbA1c testing should be performed in a laboratory, using a method that is National Glycohaemoglobin Standardization Program(NGSP-) [60] certified and standardised to the Diabetes Complications and Control Trial (DCCT) assay. All guidelines recommend similar thresholds for the diagnosis of IGT (FPG $<7.0 \mathrm{mmol} / \mathrm{L}[126 \mathrm{mg} / \mathrm{dL}]$ and/or 2 -h OGGT $\geq 7.8$ but $<11 \mathrm{mmol} / \mathrm{L}$ [200 mg/dL]) and the recommended threshold for IFG according to WHO is $6.1 \mathrm{mmol} / \mathrm{L}(110 \mathrm{mg} / \mathrm{dL})$.

\section{2. $T 2 D$ risk stratification}

In 2011, approximately 342 million people worldwide (60 million people in Europe) had T2D and another 300 million had the characteristics of pre-diabetes (e.g. insulin resistance, hyperinsulinaemia, IGT or IFG) [15]. Increasingly, evidence suggests that dysglycaemia per se is a modest causal factor for CVD; that said approximately $60 \%$ of patients with T2D will develop CVD. A major problem in the treatment of patients with pre-diabetes or T2D is that patients may not display symptoms for many years, by which time secondary complications such as coronary, cerebrovascular and microvascular disease, can be well-established. Given that the level of CV risk increases with the duration of T2D [61,62], early and effective modification of CVD risk, whilst mitigating the risk of developing/worsening T2D, would seem sensible. Indeed, the benefits of earlier T2D screening are demonstrated by a recent analysis of data from 51,526 people with newly diagnosed T2D in Scotland, in which the majority of patients were screened for T2D within an acceptable period and the prevalence of retinopathy at first screening was significantly lower than that observed in previous studies [63].

To improve the early detection and management of people with or at risk of developing T2D, the $2013 \mathrm{ESC} /$ EASD guidelines recommend a combined approach for $\mathrm{CV}$ and T2D risk screening [8]. All patients with CVD should undergo HbA1c and/or FPG testing. For the general population and in those with associated abnormalities (obesity, hypercholesterolaemia, family history of T2D etc.), a twostep approach is recommended that requires risk stratification using score charts followed by biochemical assessment only in those patients with high T2D risk. Several score charts are available for predicting the 10-year risk of developing T2D based on age, gender, ethnicity, family history of T2D and BMI. Of these, the FINnish Diabetes RIsk Score (FINDRISC [64]; Fig. 1) is commonly used in Europe, but others are equally effective $[65,66]$.

\subsection{Prevention and treatment of $T 2 D$ and $C V D$ in people with high $T 2 D$ risk}

In people with a high risk of developing T2D (including those with established IGT and/or HbAlc levels in the range $6.0-6.4 \%$ ), conversion to T2D can be delayed and, in some cases, prevented by timely intervention with intensive lifestyle changes and/or T2D medications [8,67-73]. Of these strategies, the Diabetes Prevention Program (DPP) $(N=3234)$ showed that 2.8 year's (median) treatment with lifestyle change was more effective for the reduction of incident T2D among IGT individuals than treatment with metformin ( $-58 \%$ and $-31 \%$ versus placebo, respectively) [68]. A 10-year follow-up of the DPP study $(N=2766)$, in which each patient group was assigned intensive lifestyle changes in addition to their original treatment, showed that, although the incidences of T2D during this extended follow-up period were similar in all 3 groups $(5.9 ; 95 \%$ CI 5.1-6.8 per 100 person-years with lifestyle, 4.9 [4.2-5.7] with metformin and 5.6 [4.8-6.5] with placebo), the cumulative incidence of T2D remained lowest in the lifestyle group $(-34 \%$ with lifestyle versus placebo and $-18 \%$ for metformin versus placebo) [67]. The equalisation of incidences during the DPP study was most likely due to the lifestyle change intervention offered to all three groups. A number of other studies have demonstrated similar observations [70-72], leading guidelines to recommend intensive lifestyle changes as the first-line treatment for the 


\section{Type 2 diabetes risk assessment form}

\section{Circle the right alternative and add up your points.}

\author{
1. Age \\ Op. Under 45 years \\ $2 p . \quad 45-54$ years \\ 3p. $55-64$ years \\ 4p. Over 64 years
}

\section{Body mass index \\ Op. Lower $25 \mathrm{~kg} / \mathrm{m}^{2}$ \\ 1p. $\quad 25-30 \mathrm{~kg} / \mathrm{m}^{2}$ \\ 3p. Higher than $30 \mathrm{~kg} / \mathrm{m}^{2}$}
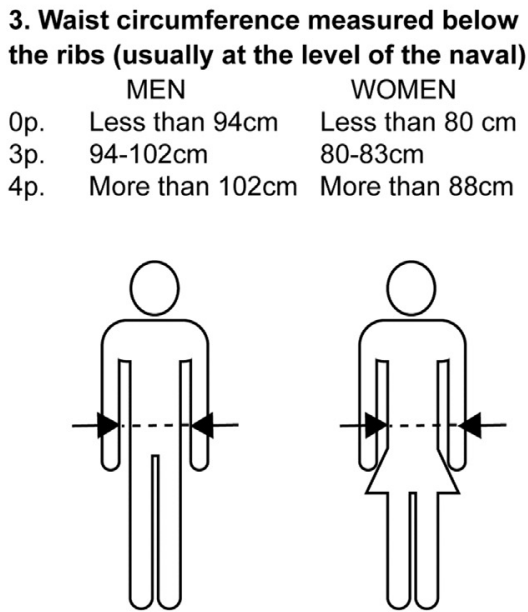

4. Do you usually have daily at least 30 min of physical activity at work and/or during leisure time (including normal daily activity)?

Op. Yes

2p. No

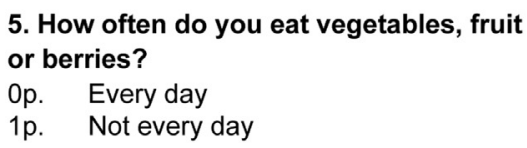

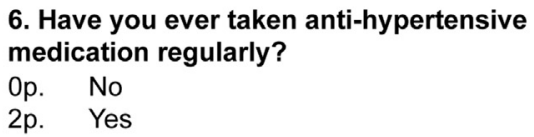

7. Have you ever been found to have high blood glucose (e.g. in a health examination, during an illness, during pregnancy)?

Op. No

5p. Yes

\section{Have any of the members of your immediate family or other relatives been diagnosed with diabetes (type 1 or 2 )? Op. No \\ 3p. Yes: grandparent, aunt, uncle or first cousin (but no own parent, brother, sister or child) \\ $5 p$. Yes; parent, brother, sister or own child}

Total risk score

The risk of developing type 2 diabetes within 10 years is

Lower than 7 Low: estimated 1 in 100

will develop disease

7-11 Slightly elevated: estimated 1 in 25 will develop disease

$12-14$ Moderate: estimated 1 in 6 will develop disease

$15-20$ High: estimated 1 in 3 will develop disease Higher Very high: than 20 estimated 1 in 2 will develop disease

Fig. 1. FINnish Diabetes Risk Score (FINDRISC) to assess the 10-year risk of developing T2D in adults. Adapted from Ryden et al [8].

prevention of T2D in patients with high T2D risk [8], followed by metformin if necessary [8].

According to international guidelines, $\mathrm{CV}$ risk reduction in people with established T2D should include a combination of intensive lifestyle changes, glycaemic control (targeting $\mathrm{HbA} 1 \mathrm{c}<7.0 \%$ ), BP reduction $[<140 / 85 \mathrm{mmHg}$, and lipid management as previously described in Section 2 $[4,8,15,58,59,74]$. However, a meta-analysis of five prospective randomised controlled trials $(N=33,040)$ showed that, although intensive glycaemic control was associated with significant reductions in $\mathrm{HbAlc}$, non-fatal MI and CHD risk, the reduction in CV events (2.9 per 200 T2D patients treated over 5 years) was far more modest than that achieved either with lipid-lowering therapy $(8.2$ fewer events for each $\mathrm{mmol} / \mathrm{L}$ reduction LDL-C) or antihypertensive treatment $(12.5$ fewer events per $4 \mathrm{mmHg}$ reduction in systolic blood pressure) [75]. In people without
T2D but with high T2D risk, The Diabetes REduction Assessment with ramipril and rosiglitazone Medication (DREAM) study $(N=5269)$ showed that treatment with rosiglitazone increased the likelihood of reversion to normoglycaemia and reduced the incidence of T2D but had little effect on CV event rates [69]. More recently, the 18month Carotid Atherosclerosis: Metformin For Insulin Resistance (CAMERA) trial demonstrated a significant reduction in glycaemia when metformin was added to a statin in non-diabetic subjects with established CVD and large waist circumference $(N=173)$ but no change in carotid intima-media thickness (CIMT) [76]. Although the Actos Now for Prevention of Diabetes (ACT NOW) trial showed a slower rate of CIMT progression in people with prediabetes treated with pioglitazone versus placebo, this result was independent of changes in glycaemia [77]. Overall, results suggest that the CV risk associated with 
dysglycaemia is modest and that lifestyle changes together with effective management of dyslipidaemia and blood pressure should be a priority for $\mathrm{CV}$ risk reduction in people with, or at risk of developing, T2D.

\section{Evidence for the diabetogenicity of statins}

The first study to report on T2D risk with statin use was the all-male West Of Scotland Coronary Prevention Study (WOSCOPS; $N=$ 5974) [37]. This study suggested that, compared to placebo, pravastatin was associated with a $30 \%$ relative risk reduction $(P=0.042)$ in the hazard of developing T2D after 5 years. Therefore, the finding in Justification for the Use of Statins in Primary Prevention: An Intervention Trial Evaluating Rosuvastatin (JUPITER) study $(N=17,802)$ that treatment with rosuvastatin $20 \mathrm{mg} /$ day for 1.9 years was associated with a significant $25 \%$ relative risk increase in T2D among middle-aged men and women with 'normal' levels of LDL-C (median $108 \mathrm{mg} / \mathrm{dL}$ ) and high levels of Creactive protein (CRP) (median $4.2 \mathrm{mg} / \mathrm{L}),(3.0 \%$ vs. $2.4 \%)$ versus placebo $(P=0.01)$, was surprising [36]. This increase was accompanied by a small but significant increase in $\mathrm{HbA1c}$ levels. Overall, these findings led to a reappraisal of the original notion that statins may lessen T2D risks.

To investigate the totality of evidence provided by all trials with relevant data, Sattar et al. carried out a metaanalysis of 13 statin trials including 91,140 patients without T2D, which involved retrieving data for several of the existing trials [39]. Overall, standard-dose statin therapy (atorvastatin $10 \mathrm{mg}$, pravastatin $40 \mathrm{mg}$, simvastatin $40 \mathrm{mg}$ or rosuvastatin $20 \mathrm{mg}$ ) was associated with a $9 \%$ increased risk for T2D over 4 years (OR 1.09; 95\% CI 1.02-1.17), with little heterogeneity $\left(I^{2}=11 \%\right)$ between trials (Fig. 2). Later, a post-hoc analysis of the Stroke Prevention by Aggressive Reduction in Cholesterol Levels (SPARCL) trial $(N=3803)$ showed that new-onset T2D developed in 166 of 1905 patients randomised to atorvastatin $80 \mathrm{mg} / \mathrm{day}$ and in 115 of 1898 patients in the placebo group $(8.71 \%$ vs. $6.06 \%$, adjusted HR: 1.37 ; 95\% CI: $1.08-1.75 ; P=0.011$ ) [41]. The implications of these results are discussed in Section 7.

\subsection{The degree of statin diabetogenicity increases with statin dose}

To further investigate and substantiate the potential effect of statins on T2D risk, Preiss et al. carried out a metaanalysis of data from five trials in which 32,752 participants without $\mathrm{T} 2 \mathrm{D}$ at baseline were randomised to receive intensive- versus standard-dose statins [38]. The study demonstrated a higher risk of developing $\mathrm{T} 2 \mathrm{D}(\mathrm{OR}, 1.12)$ in recipients of intensive-dose statins, with no apparent heterogeneity between trials $\left(I^{2}=0 \%\right)$ (Fig. 3). Together, these results suggest that the diabetogenic effects of statins are likely to be dose-related.

\subsection{People with pre-existing risk factors for $T 2 D$ are more likely to develop statin-mediated T2D than those without}

A recent post-hoc analysis of data from the Treating to New Targets (TNT) $(N=7595)$ and IDEAL $(N=7461)$ trials showed that the statin-mediated development of T2D is associated with raised FPG levels $(>100 \mathrm{mg} / \mathrm{dL})$ and by the presence of components of the metabolic syndrome, including elevated levels of fasting TGs ( $>150 \mathrm{mg} / \mathrm{dl})$, BMI $>30 \mathrm{~kg} / \mathrm{m}^{2}$, and hypertension [41,78]. Among patients with 0-1 T2D risk factors at baseline, the risk of developing T2D during a median 5 years follow up was similar among patients treated with high-dose statins (atorvastatin $80 \mathrm{mg}$ or simvastatin $40 \mathrm{mg}$ ) and moderate-dose statins (atorvastatin $10 \mathrm{mg}$ or simvastatin $20 \mathrm{mg})(3.22 \%$ vs. $3.35 \%$, respectively; HR: $0.97 ; 95 \%$ CI: $0.77-1.22$ ). Among patients with $2-4$ risk factors, T2D developed in $14.3 \%$ of the high-dose group and in $11.9 \%$ of the lower-dose groups (HR: 1.24; 95\% CI: $1.08-1.42 ; P=0.0027)$. This suggests that the dose-related diabetogenic effects of statins might be most apparent for people with pre-existing risk factors for T2D, but further research is needed to confirm this possibility.

Similarly, a recent analysis of the JUPITER study showed that, compared to placebo, rosuvastatin-treated subjects with $\geq 1$ risk factor for T2D (metabolic

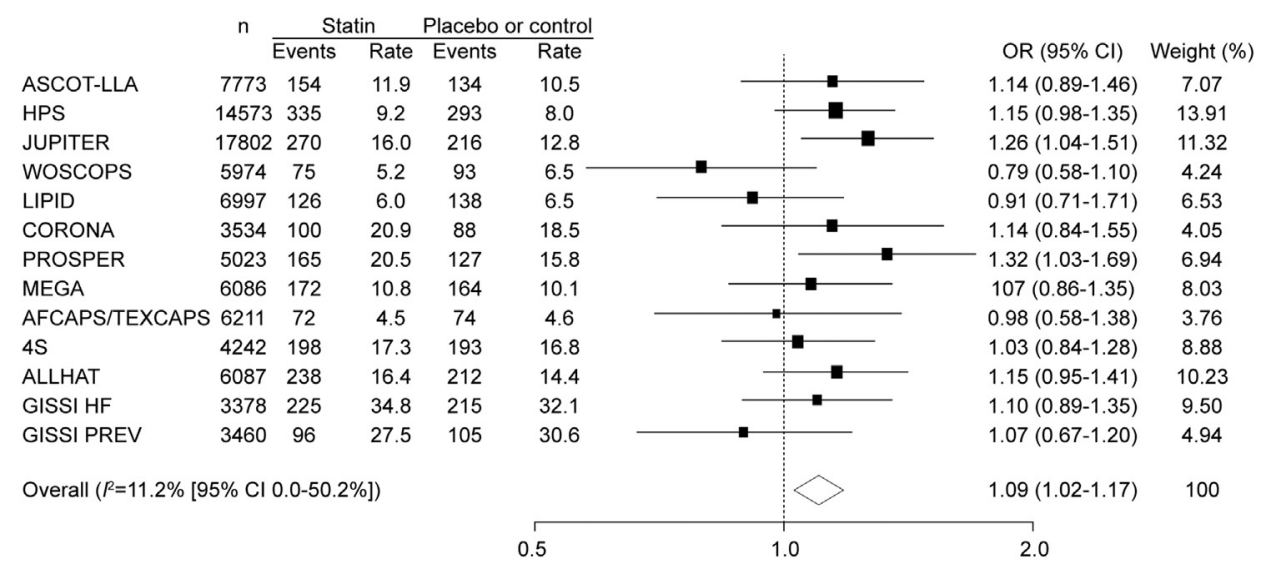

Fig. 2. Statins are associated with an increased risk of T2D. Adapted from Sattar et al. [39]. 


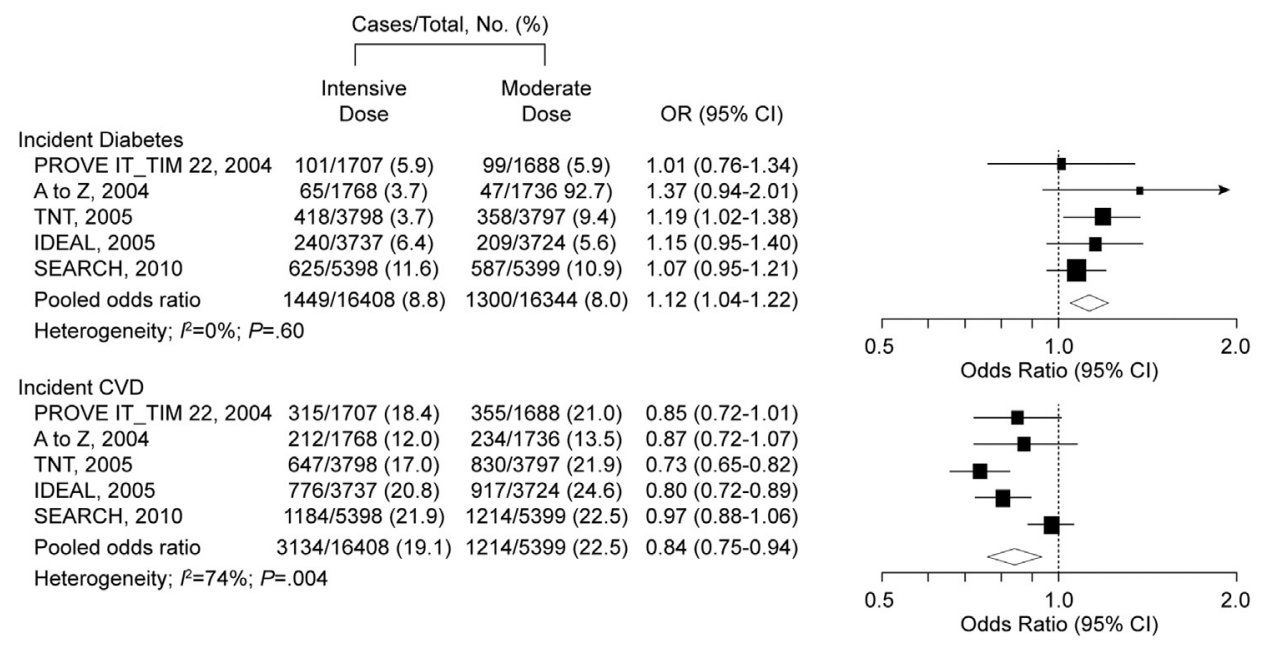

Fig. 3. The diabetogenic effects of statins appear to be dose-related. Adapted from Preiss et al [38].

syndrome, impaired FPG, BMI $>30 \mathrm{~kg} / \mathrm{m}^{2}$, or HbA1c $>6 \%$ ) had a $28 \%$ increased risk of developing T2D (HR 1.28, 95\% CI 1.07-1.54, $P=0.01$ ), whereas the risk in patients without any risk factors was negligible $[35,79]$. In this study, there was a significant $39 \%(95 \% \mathrm{CI}$ $0.47-0.79 P<0.0001)$ reduction in the primary endpoint (MI, stroke, admission to hospital for unstable angina, arterial revascularisation, or CV death) in rosuvastatintreated patients with risk factors for T2D and a 52\% (CI $0.33-0.68 P=0.0001)$ reduction in patients without. Overall, 134 total vascular events or deaths were avoided for every 54 new cases of T2D in the high-risk group, compared to 86 total vascular events or deaths with no excess of incident T2D in the low-risk group. Even in people who developed T2D (270 on rosuvastatin vs. 216 on placebo, $P=0.01$ ), the point estimate for $\mathrm{CV}$ risk reduction associated with rosuvastatin (HR $0.63,95 \%$ CI $0.25-1.60$ ) was consistent with that for the whole study (HR $0.56,95 \%$ CI 0.46-0.69). Together, these studies suggest that the short-term risk of developing T2D in patients without T2D risk factors is negligible, irrespective of the statin dose. Further studies are required to examine whether statins cause T2D per se or simply accelerate the progression to T2D in people with a pre-disposition for the disorder.

\subsection{Are the diabetogenic effects similar for all statins?}

Seven statins are currently available for the treatment of dyslipidaemia-atorvastatin, simvastatin, rosuvastatin, pitavastatin, lovastatin, pravastatin, and fluvastatin. Whereas some statins have been associated with elevations in glycaemic parameters in patients with and without T2D, others have demonstrated neutral effects $[40,42,44,45,80-95]$. However, since many of these studies did not systematically assess T2D incidence or were underpowered to detect a difference between statins, results should be treated with caution.

One of the earliest studies to demonstrate a potential difference between the diabetogenicity of statins was a post-hoc analysis of data from the Pravastatin or Atorvastatin Evaluation and Infection Therapy-Thrombolysis in Myocardial Infarction (PROVE-IT) 22 trial in which patients without pre-existing T2D $(N=3382)$ showed a $0.30 \%$ increase from baseline in HbAlc levels with atorvastatin $80 \mathrm{mg}$ and a $0.12 \%$ increase with pravastatin $40 \mathrm{mg}(P<0.0001)$ [83]. To determine whether individual statins have differing effects on insulin sensitivity (IS), a meta-analysis of 16 studies $(N=1146)$ was carried out in patients without pre-existing T2D [91]. When pooled as a class, statins had no significant effect on IS compared with placebo. However, individual comparisons showed that, whereas IS was significantly improved with pravastatin $(P=0.03$ versus placebo), there was a non-significant deterioration in IS with atorvastatin and rosuvastatin and a significant deterioration with simvastatin $(P=0.03)$. Major limitations of this analysis include between-study differences in the method used to measure IS and failure to consider varying doses or durations of statin treatment. These results should therefore be considered preliminary and further large-scale trials would be helpful.

More recently, a meta-analysis of 17 RCTs including 113,394 patients without pre-existing T2D showed that, among the three low-dose statins assessed, pravastatin $10-20 \mathrm{mg} /$ day was associated with the lowest risk for incident T2D (OR 0.90 vs placebo; 95\% CI 0.71-1.35) followed by atorvastatin $10 \mathrm{mg}(1.04 ; 0.75-1.46)$ and then rosuvastatin $10 \mathrm{mg}(1.11 ; 0.81-1.52)$ [92] (see Appendix). Although the 95\% CIs were large in these studies and overlap, the order of risk was replicated when the effects of moderate- to high-dose statins were compared (lovastatin $20-40 \mathrm{mg}<$ pravastatin $40 \mathrm{mg}<$ atorvastatin $80 \mathrm{mg}<$ simvastatin $40 \mathrm{mg}<$ rosuvastatin $20 \mathrm{mg}$ ) and results remained similar in several other ranking analyses.

A population-based cohort study carried out in 471,250 Canadian subjects without T2D showed that patients taking atorvastatin, simvastatin or rosuvastatin had an increased risk of developing T2D compared with those treated with 
pravastatin (adjusted HR 1.22 [95\% CI 1.15-1.29]; 1.10 [1.04-1.17] and 1.18 [1.10-1.26], respectively (see Appendix) [44]. This translated into an absolute risk for incident T2D of 31, 34 and 26 events per 1000 person years compared with 23 per 1000 person years for pravastatin. Crude event rates for fluvastatin and lovastatin (21.52 and 21.80 events per 1000 person years, respectively) were similar to those observed with pravastatin and the order of diabetogenicity was the same regardless of whether statins were used for the primary or secondary prevention of CVD. Although similar results were observed when statins were grouped by potency, the risk of incident T2D associated with use of rosuvastatin became non-significant (adjusted HR 1.01; 0.94-1.09) when dose was taken into account.

Finally, a retrospective cohort study carried out in 239,628 statin-treated patients from Irish primary care clinics demonstrated a significantly increased risk of incident T2D with atorvastatin (adjusted HR 1.25; 95\% CI $1.21-1.28)$, simvastatin $(1.14 ; 1.06-1.23)$ and rosuvastatin $(1.42 ; 1.33-1.52)$, but not for pravastatin $(1.02 ; 0.98-1.06)$ or fluvastatin (1.04; 0.91-1.18) (see Appendix) [45]. This study showed statistically significant overall dose and duration effects for all statins except fluvastatin, which only demonstrated a duration effect.

Whilst the above two observational studies are of interest, there remains potential for bias by factors including allocation bias. Additionally, the baseline risk of developing T2D is likely to vary between individuals allocated to different statin regimens, hence the most reliable information will likely come from meta-analyses of data from randomised controlled trials. To date, however, the only large-scale clinical trial specifically designed to investigate the effects of a statin on incident T2D is the Japan Prevention Trial of Diabetes by Pitavastatin in Patients with Impaired Glucose Tolerance (J-PREDICT) study [93]. Preliminary results from this prospective randomised, open-label, probe-design study show that lifestyle modification plus low- to moderate-dose (1-2 mg/day) pitavastatin was associated with a significant reduction in the cumulative incidence of T2D (defined either as 2-h plasma glucose $\geq 200 \mathrm{mg} / \mathrm{dL}$ or FPG $\geq 126 \mathrm{mg} / \mathrm{dL}$ measured at least once) in high-risk patients with IGT $(N=1269)$ compared to lifestyle modification alone. A number of small and/or retrospective studies examining the effects of pitavastatin on glycaemic control potentially support these results (see Appendix). However, further large-scale head-to-head trials are required to investigate the dose- and duration-effects of pitavastatin and to compare these effects with those of other high-potency statins.

Overall, the data published to date should be interpreted to indicate that the diabetogenicity of statins is a 'class effect'. However, data are still evolving and there are signals that some statins have a potentially neutral effect on glycaemic control (see Appendix). As always, results from meta-analyses and prospective studies require confirmation in large-scale head-to-head clinical trials. Further studies are also required to investigate whether the observed differences are due to diabetogenicity per se or whether they are simply due to differences in study population (i.e. age or level of $\mathrm{T} 2 \mathrm{D}$ risk at baseline), the method used to diagnose $\mathrm{T} 2 \mathrm{D}$, statin dose, and/or the potency and duration of treatment.

\section{Mechanistic rationale for the diabetogenic effects of statins}

T2D is a complex disorder characterised by both pancreatic beta cell dysfunction and insulin resistance of skeletal muscle, adipose tissue and liver. The precise reasons for the increased incidence of $\mathrm{T} 2 \mathrm{D}$ with statins have not yet been identified. Possible explanations include residual confounding factors, such as improved survival with statin treatment and a greater chance of identifying incident T2D in statin-treated patients. However, analysis of electronic medical records from 500 UK general practices (285,864 men and women aged 50-84 years) showed that, during 1.2 million person-years of follow up, the risk of developing T2D (HR 1.45; 95\% CI 1.39-1.50) was unaffected by survival rates [96]. The same observation (i.e. HR giving near identical values to OR) was evident in three of the trials with relevant data included in the comparison of diabetes risk by intensive versus standard dose statins discussed previously [38]. Another possible explanation is that, rather than causing T2D per se, statins simply accelerate its progression in people with pre-existing risk factors. Further work is needed to fully investigate this possibility.

Several biological mechanisms have been proposed for the diabetogenic effects of statins [40,43,97-99]. Under normal conditions, glucose enters pancreatic beta cells [97], skeletal muscle cells [100] and adipocytes [101] via insulinresponsive transmembrane glucose transporters (Glut 2 and Glut 4). Once inside the cell, glucose is phosphorylated by glucokinase, generating glucose-6-phosphate, which is subsequently metabolised to pyruvate. Pyruvate then enters the mitochondria, where it is metabolised as part of the tricarboxylic acid cycle to produce ATP. In beta cells, cytosolic ATP closes potassium channels, depolarises the membrane, and activates voltage-gated calcium channels, causing calcium to enter the cell and stimulate insulin secretion. In muscle, glucose is used for energy; in adipose tissue (where uptake is low), glucose is converted to fatty acids and stored as triglyceride. A number of animal and cellbased studies have reported statin-associated alterations in glucose metabolism that could result in decreased insulin secretion and/or insulin resistance [40,43,97-99]. In some of these studies, differences between statins have been observed. Further research into the mechanisms underlying statin-mediated T2D, possibly focused on mechanisms that have been linked to muscle dysfunction [102-104], will help us understand whether the potential differences in diabetogenicity between statins discussed in Section 4 (see Appendix) are real. 


\section{Further research}

In order to fully understand the best treatment strategy for people with or at risk of developing statin-mediated T2D, a number of outstanding questions need to be answered. In addition to understanding whether there are differences between statins in diabetogenic potential, studies are required to determine whether statin-mediated changes in glucose levels represent true T2D (i.e., is statin-related hyperglycaemia reversible after cessation of statin-therapy?), and, to what extent long-term statin use impairs long-term glycaemic control in patients with established T2D.

\subsection{Is the diabetogenicity of statins consistent across all patient groups?}

In general, Asian populations are more responsive to the LDL-lowering effects of statins than Caucasians, primarily due to genetic differences in statin metabolism at the level of drug transporters and hepatic enzymes [105]. However, very few studies have compared the diabetogenic effects of statins across different races. Recently, a sub-analysis of observational data from the Women's Health Initiative (WHI) suggested that, compared to statin non-users, statintreated post-menopausal women $(N=3922)$ from Asia and the Pacific Islands had a non-significant trend towards a higher risk of developing T2D (HR 1.78; 95\% CI $1.32-2.40$ ) than their Caucasian (HR $1.49 ; 1.38-1.62$ ) and African American counterparts (HR 1.18; 0.96-1.45) [106]. These results must be cautiously interpreted given the observational nature of the data.

Additional work is also required to understand the impact of age on statin diabetogenicity. Studies have shown that the risk of developing T2D increases with age, whereas the CV benefits of LDL-C-lowering are diminished [107,108]. Consequently, statin therapy (in particular high-dose statins) is substantially underused among older patients [109]. A meta-regression analysis of data from Sattar et al. [39] suggested that the association between statin therapy and the risk of incident T2D may be stronger in older versus younger participants. In contrast, no relationship was found with baseline BMI and the percentage change in LDL-C. These latter findings should be treated with caution, however, given the exploratory nature of the analyses.

\subsection{Do statin-mediated changes in glucose levels potentially attenuate their CVD risk benefits?}

Like statins, thiazide diuretics are associated with an increased risk of developing T2D [110]. The increases in blood glucose levels seen with thiazide diuretics are reversed when drugs are discontinued, even after many years of treatment [111]. Long-term studies are required to investigate the effects of statin-cessation on glycaemic control. In the meantime, statin-induced T2D should be considered and treated the same as established T2D.

\subsection{Understanding the link between dysglycaemia and CVD risk}

Recent studies have shown that, although both early- and late-onset T2D are associated with an increased risk of major CHD events and mortality, the risk associated with T2D only appears to be a CHD equivalent after a long duration ( $>10$ years) of T2D [62]. Moreover, whereas the risk of CHD events is associated with levels of FPG in the 'at-risk for T2D' and T2D range ( $>5.6 \mathrm{mmol} / \mathrm{L} ; 100 \mathrm{mg} /$ $\mathrm{dL}$ ), there appears to be only a modest correlation between FPG levels in the low-risk range $(5.6-7.0 \mathrm{mmol} / \mathrm{L}$; $101-126 \mathrm{mg} / \mathrm{dL}$ ) [51]. Together, these studies suggest that the duration of frank hyperglycaemia (i.e. sufficient to be diagnosed with T2D) contributes significantly to the association between T2D and vascular risk and that it might not be appropriate to extrapolate the glucose changes seen during statin therapy to an equivalent increase in $\mathrm{CV}$ events seen in other patients with T2D. Only robust, longer-term cohort data can address these questions.

\section{Recommendations for the use of statins in patients with, or at risk of developing, T2D}

Recommendations for the use of statins in patients at risk of developing T2D: The decision to prescribe a statin should always take into account risk vs. benefit. It is clear that the benefits of statin-use far outweigh the small absolute risk of developing T2D in patients with elevated CV risk and that, even if a patient develops T2D, the risks associated with CVD are much greater than the risks associated with T2D. Indeed, individuals with a higher risk of developing T2D have an increased risk for CVD and are therefore likely to gain greater absolute benefit from statin therapy than those with low T2D risk. Given that the current guidelines only recommend statins for patients with high- to very-high CV risk [2,3,8,11], statins should continue to be allocated based on existing CVD guidelines without regard to T2D risk. More recent reductions in CVD risk thresholds for statin treatment will still not be influenced by the diabetes risks, although of course lifestyle advice to prevent diabetes needs to be strongly reinforced.

Compared to less-intensive statin therapy, moreintensive therapy is associated with a highly significant $15 \%$ further reduction in major vascular events $(95 \% \mathrm{CI}$ $11-18 ; P<0.0001)$ [20]. However, according to a recent meta-analysis, intensifying therapy is also associated with a 12\% higher incidence of T2D [38]. This suggests that the number needed to harm per year for intensive- versus standard-dose therapy is 498 for incident T2D, whereas the number needed to treat per year is 155 for CV events. In absolute terms, intensive statin therapy accounts for 3.0 additional cases of T2D and 6.5 fewer first major $\mathrm{CV}$ events per 1000 patient-years. Again, the benefits for high- versus standard-dose statins outweigh the absolute risk of developing T2D in patients with high $\mathrm{CV}$ risk. This suggests that 
physicians should continue prescribing high-dose statins in accordance with international guidelines [2,3,8,11] (Fig. 4).

Before prescribing a statin, physicians should assess each patient's CV and T2D risk, as described in Sections 2 and 3 [8]. They should then discuss the possible consequences of statin therapy with their patients and encourage them to reduce both their CV and T2D risk through intensive lifestyle changes. Overall, available evidence suggests that the short-term risk of developing statin-mediated T2D in patients without any risk factors for T2D is low irrespective of statin dose and that the risk gradually increases with increasing numbers of T2D risk factors $[35,41,78,79]$ (Section 4). In our opinion, all patients with high CV risk considered for statins should have their risk for T2D assessed initially using a validated risk score. If their risk score shows low- to moderate-T2D risk (e.g. FINDRISC score $<15$ or equivalent using other T2D risk scores) then HbA1c and/or FPG levels need not be assessed (Fig. 4). In contrast, in patients with CVD and/or high CV risk and high- to very-high T2D risk scores (e.g. FINDRISC score $\geq 15$ or equivalent), HbA1c or FPG levels should be measured pre-statin and re-assessed 3 months after statin initiation (Fig. 4). In patients with a high T2D risk score and/or $\mathrm{FPG}>100 \mathrm{mg} / \mathrm{dL} / 5.5 \mathrm{mmol} / \mathrm{L}$ or $\mathrm{HbA} 1 \mathrm{c}$ $6.0-6.4 \%$, appropriate measures should be taken to reduce the risk of conversion from pre-diabetes to T2D. We suggest this might include targeting weight loss and reductions in glycaemia through more intensive lifestyle changes with or without T2D treatment.

\subsection{Case study 1: patient with high CV risk and high T2D risk}

A white, British, 60-year old man without CVD or T2D symptoms but with concerns about his general health presented for a health check. His BMI was $34 \mathrm{~kg} / \mathrm{m}^{2}$, his waist circumference $110 \mathrm{~cm}$, he smoked and rarely exercised. Untreated blood pressure was $155 / 90 \mathrm{mmHg}$ on repeat testing; fasting bloods revealed TG $2.5 \mathrm{mmol} / \mathrm{L}(225 \mathrm{mg} /$ $\mathrm{dL}), \mathrm{LDL}-\mathrm{C} 3.3 \mathrm{mmol} / \mathrm{L}(128 \mathrm{mg} / \mathrm{dL})$ and a non-HDL-C $4.5 \mathrm{mmol} / \mathrm{L}$ with HDL-C $1.0 \mathrm{mmol} / \mathrm{L}(39 \mathrm{mg} / \mathrm{dL})$ and total cholesterol $5.5 \mathrm{mmol} / \mathrm{L}(213 \mathrm{mg} / \mathrm{dL})$. The patient's father had an MI at the age of 52 years and was recently diagnosed with T2D. In accordance with the 2013 ESC/ EASD guidelines [8], the patient was assessed for overall $\mathrm{CV}$ risk using SCORE charts and for T2D risk using the FINDRISC chart. He was found to have a high CV risk (5\% chance of 10-year CV mortality) and a high (1 in 3) risk of developing T2D within 10 years. HbA1c level was $6.3 \%$. The physician discussed the consequences of statin therapy with the patient and advised him to reduce his CV and T2D risk through intensive lifestyle changes. A moderateintensity statin was prescribed to reduce LDL-C to $\leq 2.5 \mathrm{mmol} / \mathrm{L}(100 \mathrm{mg} / \mathrm{dL})$ and the patient was asked to return to the clinic for follow-up. After 3 months, LDL-C was below the recommended target and he had lost some weight through sustainable changes in his diet. However, his BMI remained $33 \mathrm{~kg} / \mathrm{m}^{2}$ and $\mathrm{HbAlc}$ was still $6.3 \%$. Lifestyle advice was reinforced and the patient was reassessed for LDL-C and T2D risk every year.

\subsection{Case study 2: patient with low CV risk and high T2D risk}

A 35-year old man living in France with total cholesterol $5.8 \mathrm{mmol} / \mathrm{L}(232 \mathrm{mg} / \mathrm{dL})$, LDL-C $3.5 \mathrm{mmol} / \mathrm{L}(135 \mathrm{mg} /$ $\mathrm{dL})$, TG $3.5 \mathrm{mmol} / \mathrm{L}(310 \mathrm{mg} / \mathrm{dL})$ and HDL-C $1.10 \mathrm{mmol} / \mathrm{L}$ $(43 \mathrm{mg} / \mathrm{dL})$ presented at a clinic with T2D symptoms. Both parents were diagnosed with T2D relatively early in life. The patient's BMI was $31 \mathrm{~kg} / \mathrm{m}^{2}$, waist circumference was $103 \mathrm{~cm}$, he had a sedentary lifestyle, poor diet, had never smoked and his BP was $120 / 75 \mathrm{mmHg}$. In accordance with the 2013 ESC/EASD guidelines [8], the patient was assessed for overall CV risk using SCORE charts and T2D risk using FINDRISC charts. His overall 10-year risk of CV mortality was found to be extremely low $(<1 \%)$ but his

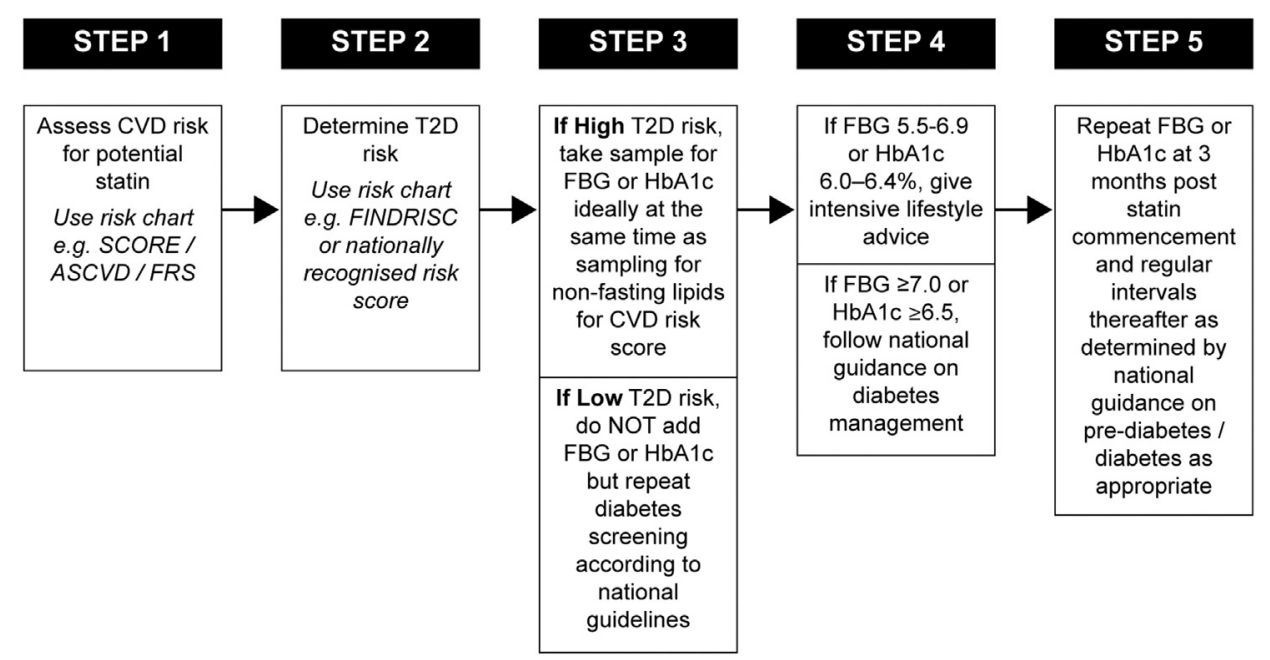

Fig. 4. Recommendations for glycaemia testing pre- and post- statin commencement in individuals without known diabetes $[3,8,11,33,55]$. 
FINDRISC score (15) was high. HbA1c levels were evaluated and found to be $6.0 \%$. The patient was given lifestyle advice and was asked to return for repeat $\mathrm{HbAlc}$ measurement. HbA1 levels were reduced to $5.8 \%$. As the patient's CV risk was low, no statins were prescribed and the patient was kept under annual review by his General Practitioner.

\subsection{Recommendations for the use of statins in patients who develop $T 2 D$ during statin treatment}

Numerous studies have shown that LDL-C-lowering using statins significantly reduces $\mathrm{CV}$ risk in people with established T2D and that further reductions in CV risk can be obtained using more- vs. less-aggressive treatment [21]. Consequently, international treatment guidelines currently recommend statins as the first-line lipid-lowering pharmacotherapy in the majority of people with T2D $[2-4,11,15,54,55]$. However, studies have yet to show whether statin-mediated changes in glucose levels represent true T2D and whether these changes can be reversed when statin treatment is stopped (Section 6). Moreover, the impact of statin-mediated T2D on both micro- and macrovascular risk is still unknown over the longer term. In general the benefits of LDL-C reduction on CVD prevention outweigh the potential CVD risk from elevated blood glucose levels. Patients that develop T2D during statin therapy should therefore continue with therapy according to national guidelines and be encouraged to reduce their risk of developing T2D-related complications (including CVD) through lifestyle changes.

\section{Conclusions}

Statins are the recommended first-line lipid-lowering drugs for the majority of patients with any level of $\mathrm{CV}$ risk. Although they are generally considered to be safe and welltolerated, recent studies have demonstrated a dosedependent increase in T2D with statins (Figs. 2 and 3). A number of plausible mechanisms have been suggested to support this effect (Section 5), but definitive proof for responsible mechanisms is lacking. Although our understanding of the diabetogenic effects of statins is increasing, more evidence is required to fully understand the impact of ethnicity, gender and age. Moreover, it is not yet known whether other drugs that increase glucose levels, such as beta-blockers and thiazide diuretics, increase the diabetogenic effect of statins or whether drugs that improve glycaemic control can attenuate potential statin-induced glycaemic changes e.g on microvascular disease. Until long-term data become available, patients with statininduced elevations in blood glucose above the T2D threshold should be treated in the same way as those developing T2D de novo.

It is clear that the benefits of statin-use for the reduction of $\mathrm{CV}$ risk far outweigh the risk of developing T2D in the majority of patients. In all cases, patients should be assessed for their risk of developing T2D both before and during statin therapy. Physicians should then discuss the possible consequences of statin treatment with their patients and strongly encourage them to reduce both their $\mathrm{CV}$ and T2D risk through lifestyle changes. There is currently no evidence to suggest that a patient who develops T2D during statin treatment should discontinue treatment. Broadly speaking, patients should continue with their statin therapy in accordance with national guidelines, and the statin link to T2D should be used to further incentivise patients to adhere with lifestyle changes.

\section{Conflict of interest}

Naveed Sattar has consulted for Astrazeneca, BMS, BI, Amgen, Sanofi, and Kowa; Henry Ginsberg reports have received consulting fees from: Kowa, Merck, Pfizer, AstraZeneca, BMS, Sanofi, Regeneron, Amgen, Novartis. Research funding from Merck, Sanofi, Regeneron, Genzyme, Amgen, Novartis.

Kausik Ray reports to having received honoraria for advisory boards or lectures from Agerion, Abbott, Pfizer, AZ, Sanofi, Regeneron, Amgen, MSD, Roche, Kowa, Novartis, Novo Nordisk, Daiichi, Bayer and Lily. John M. Chapman: Research funding from Pfizer, Kowa, Merck, CSL Consultancy fees from Fondation Leducq, Merck, Kowa, Danone, Amgen, Sanofi-Regeneron.

Marcello Arca: Lecture honoraria, consultancy fees and research funding from Merck Sharp \& Dohme, Pfizer, Asta Zeneca, Kowa, Sanofi, Regeneron, Roche, Genzyme, Abbott, Boehringer, Aegerion, Mediolanum, SigmaTau, Menarini.

Maurizio Averna: Consultancy fees from Aegerion, Genzyme, MSD, Roche, Kowa, Amgen, AstraZeneca, Sanofi. Participation as a speaker at scientific congresses from Aegerion, AstraZeneca, MSD, Mediolanum, Sanofi, Amgen.

D. John Betteridge: Honoraria/lecture fees from the following companies in the past 2 years; AstraZeneca, Pfizer, Takeda, Janssen, MSD, Kowa, Sanofi-aventis, Amgen.

Rafael Carmena: Lecture fees and honoraria from advisory boards from MSD, Pfizer, AstraZeneca, and Takeda.

Raimund Erbel: Steering committee member for AstraZeneca.

Xavier Garcia-Moll: Consultancy fees from AstraZeneca, Kowa, Merck Sharpe \& Dohme.

Janusz Gumprecht: Consulting honoraria from KOWA.

Shun Ishibashi: Research grants and/or lecture fees from Kowa, Daiichi Sankyo, Merck Sharp \& Dohme, Novartis, Pfizer, AstraZeneca, Shionogi, and Astellas.

John JP Kastelein: Consultant to and receives honoraria from Boehringer Ingelheim, Kowa, AstraZeneca, Pfizer and Eli Lilly.

Vincent Maher: Research funding from MSD, Pfizer and honoraria fees for lecturing from Menarini, Astra, MSD. Pfizer and Servier. 
Pedro Marques da Silva: Lecture honoraria or consulting fees from Abbott, AstraZeneca, Bayer, JABA-Recordati, MSD, Kowa Pharmaceuticals, Novartis, and Tecnimede.

Luis Masana: Advisory and lecture fees from KOWA, Amgen, Sanofi, MSD, Esteve, Danone, Praxis.

Masato Odawara: Research grants and lecture fees from Astellas, AstraZeneca Daiichi Sankyo, Kowa, Merck Sharpe \& Dohme, Novartis, Pfizer and Shionogi.

Terje Pedersen: Lecture fees from AstraZeneca, MSD, Amgen and Pfizer. Advisory Board fees from MSD, Amgen and Kowa Pharmaceuticals.

Tamio Teramoto: Personal fees from Astellas KK, Bayer KK, Daiichi Sankyo KK, Kissei KK, Kowa KK, MSD KK Pfizer KK, Shionogi KK.

Lale Tokgozoglu: Honoraria from Abbott, Actelion, AstraZeneca, Bayer, Boehringer-Ingelheim, Daiichi Sankyo, Kowa, MSD, Novartis, Pfizer, Roche, Sanofi, Servier.

Peter P Toth: Speakers bureau: Amarin, AstraZeneca, Genzyme, GSK, Kowa, Merck; Consultant: Amgen, AstraZeneca, Atherotech, Kowa, Liposcience, Merck.

Paul Valensi: Lectures for Abbott, Bayer, Bristol Myers Squibb-AstraZeneca, Eli-Lilly, GlaxoSmithKline, Merck
Santé, Merck Sharp Dohme, Novo Nordisk, Novartis, Pierre Fabre. He has participated to Expert Committees for or his department has received research grants from Abbott, Bayer, Bristol Myers Squibb-AstraZeneca, Boehringer Ingelheim, Daiichi-Sankyo, GlaxoSmithKline, Kowa, Lilly, Merck Santé, Novo Nordisk.

Bruno Vergès: Fees from AstraZeneca/Bristol-Myers Squibb, Bayer Pharma, Kowa, Lilly, Merck Sharp Dohme, Novartis, Novo Nordisk, Sanofi, Servier and Takeda.

Deepak Bhatnagar, Helen Bilianou, Richard Češka, Alberto Corsini, Paul D. Flynn, Selim Jambart, Carlo Maria Rotella, and Ibrahim Salti have no conflicts of interest to report.

\section{Funding declaration}

Publication of this supplement has been funded by Kowa Pharmaceutical Europe. Pitavastatin is a product marketed by the sponsor of the supplement. Authors received support with the preparation of their articles from GK Pharmacomm, an agency funded by the sponsor. The sponsor had no input in terms of the content of this supplement.

Appendix

Studies comparing the diabetogenic effects of statins.

\begin{tabular}{|c|c|c|c|c|}
\hline Statin & Patient characteristics & Study design $(\mathrm{N})$ & $\begin{array}{l}\text { Mean } \\
\text { follow up }\end{array}$ & Main observations \\
\hline Rosuvastatin $10 \mathrm{mg}$ [92] & Mixed & Meta-analysis $(N=113,394)$ & $>1$ year & $\begin{array}{l}\text { Increased risk of T2D vs placebo (OR } 1.11 ; 95 \% \\
\text { CI } 0.81-1.52 \text { ) }\end{array}$ \\
\hline Rosuvastatin $10-40 \mathrm{mg}$ [44] & $\begin{array}{l}\text { Primary/secondary } \\
\text { prevention; age } \geq 66 \text { yrs }\end{array}$ & $\begin{array}{l}\text { Population-based cohort study } \\
(N=471,250)\end{array}$ & 14 years & $\begin{array}{l}\text { Increased risk of T2D vs pravastatin (adjusted } \\
\text { HR } 1.18 ; 1.10-1.26 \text { ) }\end{array}$ \\
\hline Rosuvastatin $10-40 \mathrm{mg}$ [45] & Primary prevention & $\begin{array}{l}\text { Retrospective cohort study } \\
(N=239,628)\end{array}$ & 6 years & $\begin{array}{l}\text { Increased risk of T2D vs no statin (adjusted HR } \\
1.42 ; 1.33-1.52 \text { ) }\end{array}$ \\
\hline Simvastatin $10-80 \mathrm{mg}$ [44] & $\begin{array}{l}\text { Primary/secondary } \\
\text { prevention; age } \geq 66 \text { yrs }\end{array}$ & $\begin{array}{l}\text { Population-based cohort study } \\
(N=471,250)\end{array}$ & 14 years & $\begin{array}{l}\text { Increased risk of T2D vs pravastatin (adjusted } \\
\text { HR } 1.10 ; 1.04-1.17 \text { ) }\end{array}$ \\
\hline Simvastatin $10-80 \mathrm{mg}$ [45] & Primary prevention & $\begin{array}{l}\text { Retrospective cohort study } \\
(N=239,628)\end{array}$ & 6 years & $\begin{array}{l}\text { Increased risk of T2D vs no statin (adjusted HR } \\
1.14 ; 1.06-1.23 \text { ) }\end{array}$ \\
\hline Atorvastatin $10 \mathrm{mg}$ [92] & Mixed & Meta-analysis $(N=113,394)$ & $>1$ year & $\begin{array}{l}\text { Slightly increased risk of T2D vs placebo (OR } \\
1.04 ; 95 \% \text { CI } 0.75-1.46 \text { ) }\end{array}$ \\
\hline Atorvastatin $10-80 \mathrm{mg}[44]$ & $\begin{array}{l}\text { Primary/secondary } \\
\text { prevention; age } \geq 66 \text { yrs }\end{array}$ & $\begin{array}{l}\text { Population-based cohort study } \\
(N=471,250)\end{array}$ & 14 years & $\begin{array}{l}\text { Increased risk of T2D vs pravastatin (adjusted } \\
\text { HR } 1.22 ; 1.15-1.29 \text { ) }\end{array}$ \\
\hline Atorvastatin $10-80 \mathrm{mg}[45]$ & Primary prevention & $\begin{array}{l}\text { Retrospective cohort study } \\
(N=239,628)\end{array}$ & 6 years & $\begin{array}{l}\text { Increased risk of T2D vs no statin (adjusted HR } \\
1.25 ; 1.21-1.28 \text { ) }\end{array}$ \\
\hline Pravastatin $10-40 \mathrm{mg}$ [92] & Mixed & Meta-analysis $(N=113,394)$ & $>1$ year & $\begin{array}{l}\text { Reduced risk of T2D versus placebo (OR } 0.90 \text {; } \\
95 \% \text { CI } 0.71-1.35 \text { ) }\end{array}$ \\
\hline Pravastatin $10-40 \mathrm{mg}$ [45] & Primary prevention & $\begin{array}{l}\text { Retrospective cohort study } \\
(N=239,628)\end{array}$ & 6 years & $\begin{array}{l}\text { No change in T2D risk vs no statin (adjusted HR } \\
1.02 ; 0.98-1.06 \text { ) }\end{array}$ \\
\hline Pitavastatin 1-2 mg [93] & Japanese patients with IGT & $\begin{array}{l}\text { Prospective randomised, open- } \\
\text { label, probe design }(N=1269)\end{array}$ & & Reduced risk of T2D vs lifestyle changes \\
\hline Pitavastatin 4 mg [94] & $\begin{array}{l}\text { Primary hyperlipidaemia/ } \\
\text { mixed } \\
\text { dyslipidaemia } \pm \text { metabolic } \\
\text { syndrome }\end{array}$ & $\begin{array}{l}\text { Prespecified safety analysis } \\
\text { of the randomised, double-blind, } \\
\text { PREVAIL US study comparing } \\
\text { pitavastatin }(n=164) \text { with } \\
\text { pravastatin }(n=164)\end{array}$ & 12 weeks & $\begin{array}{l}\text { No clinically-relevant glycaemic changes vs } \\
\text { baseline for pitavastatin or pravastatin }\end{array}$ \\
\hline Pitavastatin $4 \mathrm{mg}$ [95] & $\begin{array}{l}\text { Primary hyperlipidaemia/ } \\
\text { mixed dyslipidaemia }+\geq 2 \\
\text { additional CHD risk factors }\end{array}$ & $\begin{array}{l}\text { Prospective Phase } 3 \text { study } \\
\text { comparing pitavastatin } 4 \mathrm{mg} \\
(n=111) \text { with simvastatin } 40 \mathrm{mg} \\
(n=49)\end{array}$ & 56 weeks & $\begin{array}{l}\text { Pitavastatin: No change in FPG vs baseline at } 12 \\
\text { or } 56 \text { weeks; Simvastatin: No change in FPG } \\
\text { after } 12 \text { weeks; significant increase in FPG after } \\
56 \text { weeks }\end{array}$ \\
\hline Pitavastatin 1-4 mg [85] & Japanese patients with $\mathrm{T} 2 \mathrm{D}$ & $\begin{array}{l}\text { Subanalysis }(N=308) \text { of the } \\
\text { prospective post-marketing } \\
\text { surveillance LIVES study }\end{array}$ & 104 weeks & $\begin{array}{l}\text { Significant }(P<0.001) 0.28 \% \text { decrease in } \\
\text { HbA1c levels vs no treatment }\end{array}$ \\
\hline
\end{tabular}




\section{References}

[1] Nichols M, Townsend N, Luengo-Fernandex R, et al. European Cardiovascular Disease Statistics. Available at: http://www.escardio. org/about/what/advocacy/EuroHeart/Pages/2012-CVD-statistics. aspx; 2012.

[2] Perk J, De BG, Gohlke H, et al. European guidelines on cardiovascular disease prevention in clinical practice (Version 2012): the Fifth Joint Task Force of the European Society of Cardiology and Other Societies on Cardiovascular Disease Prevention in Clinical Practice. Int J Behav Med 2012;19:403-88.

[3] Reiner Z, Catapano AL, De BG, et al. ESC/EAS guidelines for the management of dyslipidaemias: the Task Force for the management of dyslipidaemias of the European Society of Cardiology (ESC) and the European Atherosclerosis Society (EAS). Eur Heart J 2011;32: $1769-818$

[4] Standards of medical care in diabetes-2014. Diabetes Care 2014; 37(Suppl. 1):S14-80.

[5] Mancia G. Total cardiovascular risk: a new treatment concept. J Hypertens Suppl 2006;24:S17-24.

[6] Cohen JD, Cziraky MJ, Cai Q, et al. 30-year trends in serum lipids among United States adults: results from the National Health and Nutrition Examination Surveys II, III, and 1999-2006. Am J Cardiol 2010;106:969-75.

[7] Yusuf S, Hawken S, Ounpuu S, et al. Effect of potentially modifiable risk factors associated with myocardial infarction in 52 countries (the INTERHEART study): case-control study. Lancet 2004; 364:937-52.

[8] Ryden L, Grant PJ, Anker SD, et al. ESC guidelines on diabetes, pre-diabetes, and cardiovascular diseases developed in collaboration with the EASD: the Task Force on diabetes, pre-diabetes, and cardiovascular diseases of the European Society of Cardiology (ESC) and developed in collaboration with the European Association for the Study of Diabetes (EASD). Eur Heart J 2013;34: 3035-87.

[9] Grundy SM, Cleeman JI, Merz CN, et al. Implications of recent clinical trials for the National Cholesterol Education Program Adult Treatment Panel III Guidelines. J Am Coll Cardiol 2004;44: $720-32$.

[10] Reiner Z. Statins in the primary prevention of cardiovascular disease. Nat Rev Cardiol 2013;10:453-64.

[11] Stone NJ, Robinson J, Lichtenstein AH, et al. 2013 ACC/AHA guideline on the treatment of blood cholesterol to reduce atherosclerotic cardiovascular risk in adults: a report of the American College of Cardiology/American Heart Association Task Force on Practice Guidelines. Circulation. Epub ahead of print. Available at: http://circ.ahajournals.org/content/early/2013/11/11/01.cir. 0000437738.63853.7a.long; 2013.

[12] Kotseva K, Wood D, De BG, et al. EUROASPIRE III. Management of cardiovascular risk factors in asymptomatic high-risk patients in general practice: cross-sectional survey in 12 European countries. Eur J Cardiovasc Prev Rehabil 2010;17:530-40.

[13] Nichols M, Townsend N, Scarborough P, et al. Trends in agespecific coronary heart disease mortality in the European Union over three decades: 1980-2009. Eur Heart J 2013;34:3017-27.

[14] Nordestgaard BG, Palmer TM, Benn M, et al. The effect of elevated body mass index on ischemic heart disease risk: causal estimates from a Mendelian randomisation approach. PLoS Med 2012;9:e1001212.

[15] International Diabetes Federation. Global guidelines for Type 2 diabetes. Available at: http://www.idf.org/sites/default/files/IDF\% 20Guideline\%20for\%20Type\%202\%20Diabetes.pdf; 2012.

[16] Mathers CD, Loncar D. Projections of global mortality and burden of disease from 2002 to 2030. PLoS Med 2006;3:e442.

[17] Lindstrom J, Neumann A, Sheppard KE, et al. Take action to prevent diabetes-the IMAGE toolkit for the prevention of type 2 diabetes in Europe. Horm Metab Res 2010;42(Suppl. 1):S37-55.
[18] O'Donnell MJ, Xavier D, Liu L, et al. Risk factors for ischaemic and intracerebral haemorrhagic stroke in 22 countries (the INTERSTROKE study): a case-control study. Lancet 2010;376: $112-23$.

[19] Baigent C, Keech A, Kearney PM, et al. Efficacy and safety of cholesterol-lowering treatment: prospective meta-analysis of data from 90,056 participants in 14 randomised trials of statins. Lancet 2005;366:1267-78.

[20] Baigent C, Blackwell L, Emberson J, et al. Efficacy and safety of more intensive lowering of LDL cholesterol: a meta-analysis of data from 170,000 participants in 26 randomised trials. Lancet 2010;376: $1670-81$.

[21] Kearney PM, Blackwell L, Collins R, et al. Efficacy of cholesterollowering therapy in 18,686 people with diabetes in 14 randomised trials of statins: a meta-analysis. Lancet 2008;371:117-25.

[22] Mihaylova B, Emberson J, Blackwell L, et al. The effects of lowering LDL cholesterol with statin therapy in people at low risk of vascular disease: meta-analysis of individual data from 27 randomised trials. Lancet 2012;380:581-90.

[23] Hsia J, MacFadyen JG, Monyak J, et al. Cardiovascular event reduction and adverse events among subjects attaining low-density lipoprotein cholesterol $<50 \mathrm{mg} / \mathrm{dl}$ with rosuvastatin. The JUPITER trial (Justification for the Use of Statins in Prevention: an Intervention Trial Evaluating Rosuvastatin). J Am Coll Cardiol 2011;57:1666-75.

[24] Taylor F, Huffman MD, Macedo AF, et al. Statins for the primary prevention of cardiovascular disease. Cochrane Database Syst Rev 2013;1:CD004816. Available at: http://www.ncbi.nlm.nih.gov/ pubmed/23440795.

[25] Nissen SE, Nicholls SJ, Sipahi I, et al. Effect of very high-intensity statin therapy on regression of coronary atherosclerosis: the ASTEROID trial. J Am Med Assoc 2006;295:1556-65.

[26] Nicholls SJ, Ballantyne CM, Barter PJ, et al. Effect of two intensive statin regimens on progression of coronary disease. N Engl J Med 2011;365:2078-87.

[27] Alberton M, Wu P, Druyts E, et al. Adverse events associated with individual statin treatments for cardiovascular disease: an indirect comparison meta-analysis. QJM 2012;105:145-57.

[28] Jones PH, Davidson MH, Stein EA, et al. Comparison of the efficacy and safety of rosuvastatin versus atorvastatin, simvastatin, and pravastatin across doses (STELLAR* Trial). Am J Cardiol 2003;92: $152-60$

[29] Kashani A, Phillips CO, Foody JM, et al. Risks associated with statin therapy: a systematic overview of randomized clinical trials. Circulation 2006;114:2788-97.

[30] Dale KM, Coleman CI, Henyan NN, et al. Statins and cancer risk: a meta-analysis. J Am Med Assoc 2006;295:74-80.

[31] Muldoon MF, Barger SD, Ryan CM, et al. Effects of lovastatin on cognitive function and psychological well-being. Am J Med 2000; 108:538-46.

[32] Nielsen SF, Nordestgaard BG, Bojesen SE. Statin use and reduced cancer-related mortality. N Engl J Med 2012;367:1792-802.

[33] Hoffman KB, Kraus C, Dimbil M, et al. A survey of the FDA's AERS database regarding muscle and tendon adverse events linked to the statin drug class. PLoS One 2012;7:e42866.

[34] Merck \& Co.. Simvastatin (Zocor) Prescribing Information. Available at: http://www.merck.com/product/usa/pi_circulars/z/zocor/ zocor_pi.pdf; 2013.

[35] Ridker PM, Pradhan A, MacFadyen JG, et al. Cardiovascular benefits and diabetes risks of statin therapy in primary prevention: an analysis from the JUPITER trial. Lancet 2012;380:565-71.

[36] Ridker PM, Danielson E, Fonseca FA, et al. Rosuvastatin to prevent vascular events in men and women with elevated C-reactive protein. N Engl J Med 2008;359:2195-207.

[37] Freeman DJ, Norrie J, Sattar N, et al. Pravastatin and the development of diabetes mellitus: evidence for a protective treatment effect 
in the West of Scotland Coronary Prevention Study. Circulation 2001;103:357-62.

[38] Preiss D, Seshasai SR, Welsh P, et al. Risk of incident diabetes with intensive-dose compared with moderate-dose statin therapy: a metaanalysis. J Am Med Assoc 2011;305:2556-64.

[39] Sattar N, Preiss D, Murray HM, et al. Statins and risk of incident diabetes: a collaborative meta-analysis of randomised statin trials. Lancet 2010;375:735-42.

[40] Sattar N, Taskinen MR. Statins are diabetogenic-myth or reality? Atheroscler Suppl 2012;13:1-10.

[41] Waters DD, Ho JE, DeMicco DA, et al. Predictors of new-onset diabetes in patients treated with atorvastatin: results from 3 large randomized clinical trials. J Am Coll Cardiol 2011;57: $1535-45$.

[42] Rocco MB. Statins and diabetes risk: fact, fiction, and clinical implications. Cleve Clin J Med 2012;79:883-93.

[43] Goldstein MR, Mascitelli L. Do statins cause diabetes? Curr Diab Rep 2013;13:381-90.

[44] Carter AA, Gomes T, Camacho X, et al. Risk of incident diabetes among patients treated with statins: population based study. Brit Med J 2013;346:f2610.

[45] Zaharan NL, Williams D, Bennett K. Statins and risk of treated incident diabetes in a primary care population. Br J Clin Pharmacol 2013;75:1118-24.

[46] Shepherd J, Blauw GJ, Murphy MB, et al. Pravastatin in elderly individuals at risk of vascular disease (PROSPER): a randomised controlled trial. Lancet 2002;360:1623-30.

[47] Mills EJ, Wu P, Chong G, et al. Efficacy and safety of statin treatment for cardiovascular disease: a network meta-analysis of 170,255 patients from 76 randomized trials. QJM 2011;104: 109-24.

[48] Ray K. Statin diabetogenicity: guidance for clinicians. Cardiovase Diabetol 2013;12(Suppl. 1):S3.

[49] Taylor KS, Heneghan CJ, Farmer AJ, et al. All-cause and cardiovascular mortality in middle-aged people with Type 2 diabetes compared with people without diabetes in a large U.K. primary care database. Diabetes Care 2013;36:2366-71.

[50] Sarwar N, Gao P, Seshasai SR, et al. Diabetes mellitus, fasting blood glucose concentration, and risk of vascular disease: a collaborative meta-analysis of 102 prospective studies. Lancet 2010;375: $2215-22$.

[51] Seshasai SR, Kaptoge S, Thompson A, et al. Diabetes mellitus, fasting glucose, and risk of cause-specific death. N Engl J Med 2011;364:829-41.

[52] FDA drug safety communication: important safety label changes to cholesterol-lowering statin drugs. Available from: http://www.fda. gov/Drugs/DrugSafety/ucm293101.html; 2012.

[53] Graham I, Atar D, Borch-Johnsen K, et al. European guidelines on cardiovascular disease prevention in clinical practice. Fourth Joint Task Force of the European Society of Cardiology and other societies on cardiovascular disease prevention in clinical practice. Eur J Cardiovasc Prev Rehabil 2007;14(Suppl. 2):S1-113.

[54] Third report of the National Cholesterol Education Program (NCEP) Expert Panel on detection, evaluation, and treatment of high blood cholesterol in adults (Adult Treatment Panel III) final report. Circulation 2002;106:3143-421.

[55] Anderson TJ, Gregoire J, Hegele RA, et al. 2012 update of the Canadian Cardiovascular Society guidelines for the diagnosis and treatment of dyslipidemia for the prevention of cardiovascular disease in the adult. Can J Cardiol 2013;29:151-67.

[56] Di Angelantonio E, Sarwar N, Perry P, et al. Major lipids, apolipoproteins, and risk of vascular disease. J Am Med Assoc 2009;302: 1993-2000.

[57] Chapman MJ, Ginsberg HN, Amarenco P, et al. Triglyceride-rich lipoproteins and high-density lipoprotein cholesterol in patients at high risk of cardiovascular disease: evidence and guidance for management. Eur Heart J 2011;32:1345-61.
[58] Definition, diagnosis and classification of diabetes mellitus and its complications: Report of a WHO consultation. Part 1. Diagnosis and classification of diabetes mellitus. World Health Organisation. Available from: http://www.who.int/diabetes/publications/en/; 2010.

[59] World Health Organisation (WHO). Use of glycated haemoglobin $(\mathrm{HbAlc})$ in the diagnosis of diabetes mellitus. Available at: http:// www.who.int/diabetes/publications/report-hba1c_2011.pdf; 2011.

[60] Little RR, Rohlfing CL, Wiedmeyer HM, et al. The national glycohemoglobin standardization program: a five-year progress report. Clin Chem 2001;47:1985-92.

[61] Sattar N. Revisiting the links between glycaemia, diabetes and cardiovascular disease. Diabetologia 2013;56:686-95.

[62] Wannamethee SG, Shaper AG, Whincup PH, et al. Impact of diabetes on cardiovascular disease risk and all-cause mortality in older men: Influence of age at onset, diabetes duration, and established and novel risk factors. Arch Intern Med 2011;171:404-10.

[63] Looker HC, Nyangoma SO, Cromie D, et al. Diabetic retinopathy at diagnosis of type 2 diabetes in Scotland. Diabetologia 2012;55: $2335-42$.

[64] Schwarz PE, Li J, Lindstrom J, et al. Tools for predicting the risk of type 2 diabetes in daily practice. Horm Metab Res 2009;41: 86-97.

[65] Abbasi A, Peelen LM, Corpeleijn E, et al. Prediction models for risk of developing type 2 diabetes: systematic literature search and independent external validation study. Brit Med J 2012;345:e5900.

[66] Chatterton H, Younger T, Fischer A, et al. Risk identification and interventions to prevent type 2 diabetes in adults at high risk: summary of NICE guidance. Brit Med J 2012;345:e4624.

[67] Knowler WC, Fowler SE, Hamman RF, et al. 10-year follow-up of diabetes incidence and weight loss in the Diabetes Prevention Program Outcomes Study. Lancet 2009;374:1677-86.

[68] Knowler WC, Barrett-Connor E, Fowler SE, et al. Reduction in the incidence of type 2 diabetes with lifestyle intervention or metformin. N Engl J Med 2002;346:393-403.

[69] Gerstein HC, Yusuf S, Bosch J, et al. Effect of rosiglitazone on the frequency of diabetes in patients with impaired glucose tolerance or impaired fasting glucose: a randomised controlled trial. Lancet 2006;368:1096-105.

[70] Pan XR, Li GW, Hu YH, et al. Effects of diet and exercise in preventing NIDDM in people with impaired glucose tolerance. The Da Qing IGT and Diabetes Study. Diabetes Care 1997;20:537-44.

[71] Lindstrom J, Ilanne-Parikka P, Peltonen M, et al. Sustained reduction in the incidence of type 2 diabetes by lifestyle intervention: follow-up of the Finnish Diabetes Prevention Study. Lancet 2006; 368:1673-9.

[72] Eriksson KF, Lindgarde F. No excess 12-year mortality in men with impaired glucose tolerance who participated in the Malmo Preventive Trial with diet and exercise. Diabetologia 1998;41:1010-6.

[73] DeFronzo RA, Tripathy D, Schwenke DC, et al. Pioglitazone for diabetes prevention in impaired glucose tolerance. N Engl J Med 2011;364:1104-15.

[74] American Diabetes Association. Management of dyslipidemia in adults with diabetes. Diabetes Care 2011;34:S12-47.

[75] Ray KK, Seshasai SR, Wijesuriya S, et al. Effect of intensive control of glucose on cardiovascular outcomes and death in patients with diabetes mellitus: a meta-analysis of randomised controlled trials. Lancet 2009;373:1765-72.

[76] Preiss D, Lloyd SM, Ford I, et al. Metformin for non-diabetic patients with coronary heart disease (the CAMERA study): a randomised controlled trial. Lancet Diabetes Endocrinol 2013. http:// dx.doi.org/10.1016/S2213-8587(13)70152-9.

[77] Saremi A, Schwenke DC, Buchanan TA, et al. Pioglitazone slows progression of atherosclerosis in prediabetes independent of changes in cardiovascular risk factors. Arterioscler Thromb Vasc Biol 2013;33:393-9.

[78] Waters DD, Ho JE, Boekholdt SM, et al. Cardiovascular event reduction versus new-onset diabetes during atorvastatin therapy: 
effect of baseline risk factors for diabetes. J Am Coll Cardiol 2013; $61: 148-52$.

[79] Watts GF, Ooi EM. Balancing the cardiometabolic benefits and risks of statins. Lancet 2012;380:541-3.

[80] Betteridge DJ, Gibson JM. Effects of rosuvastatin on lipids, lipoproteins and apolipoproteins in the dyslipidaemia of diabetes. Diabet Med 2007;24:541-9.

[81] Colhoun HM, Betteridge DJ, Durrington PN, et al. Primary prevention of cardiovascular disease with atorvastatin in type 2 diabetes in the Collaborative Atorvastatin Diabetes Study (CARDS): multicentre randomised placebo-controlled trial. Lancet 2004;364:685-96.

[82] Koh KK, Quon MJ, Han SH, et al. Atorvastatin causes insulin resistance and increases ambient glycemia in hypercholesterolemic patients. J Am Coll Cardiol 2010;55:1209-16.

[83] Sabatine MS, Wiviott SD, Morrow DA, et al. High-dose atorvastatin associated with worse glycemic control: a PROVE-IT TIMI 22 substudy. Circulation 2004;110(Suppl. 3):834.

[84] Yokote K, Saito Y. Influence of statins on glucose tolerance in patients with type 2 diabetes mellitus: subanalysis of the collaborative study on hypercholesterolemia drug intervention and their benefits for atherosclerosis prevention (CHIBA study). J Atheroscler Thromb 2009;16:297-8.

[85] Teramoto T, Shimano H, Yokote K, et al. New evidence on pitavastatin: efficacy and safety in clinical studies. Expert Opin Pharmacother 2010;11:817-28.

[86] Teramoto T, Urashima M, Shimano H, et al. A large-scale study on cardio-cerebrovascular events during pitavastatin (LIVALO tablet) therapy in Japanese patients with hypercholesterolemia LIVES 5year extension study. Jpn Pharmacol Ther 2011;39:789-803.

[87] Saku K, Zhang B, Noda K. Randomized head-to-head comparison of pitavastatin, atorvastatin, and rosuvastatin for safety and efficacy (quantity and quality of LDL): the PATROL trial. Circ J 2011;75: $1493-505$.

[88] Sponseller CA, Morgan RE, Campbell SE. Pitavastatin $4 \mathrm{mg}$ significantly reduces LDL-P and increases HDL size compared with pravastatin 40 mg (PREVAIL US). J Clin Lipidol 2012;6:288-9.

[89] Chapman MJ, Orsoni A, Robillard P, et al. Effect of high-dose pitavastatin on glucose homeostasis in patients at elevated risk of new-onset diabetes: insights from the CAPITAIN and PREVAIL-US studies. Curr Med Res Opin 2014. http://dx.doi.org/10.1185/ 03007995.2013.874989.

[90] Bellia A, Rizza S, Lombardo MF, et al. Deterioration of glucose homeostasis in type 2 diabetic patients one year after beginning of statins therapy. Atherosclerosis 2012;223:197-203.

[91] Baker WL, Talati R, White CM, et al. Differing effect of statins on insulin sensitivity in non-diabetics: a systematic review and metaanalysis. Diabetes Res Clin Pract 2010;87:98-107.

[92] Navarese EP, Buffon A, Andreotti F, et al. Meta-analysis of impact of different types and doses of statins on new-onset diabetes mellitus. Am J Cardiol 2013;111:1123-30.

[93] Odawara M, Yamazaki T, Kishimoto J, et al. Pitavastatin for the delay or prevention of diabetes development in individuals with impaired glucose tolerance. Chicago, IL, USA: 73rd American Diabetes Association. . Avaialble at: http://www.abstractsonline. $\mathrm{com} /$ plan/ViewAbstract.aspx $? \mathrm{mID}=3217 \&$ sey $=0687 \mathrm{e} 7 \mathrm{c} 8-\mathrm{c} 97 \mathrm{~d}-$ 442b-92ec-ae505e051854\&cKey=b4ea3c2f-884e-44d3-b9b1-
86846eadbd1d\&mKey=\%7B89918D6D-3018-4EA9-9D4F711F98A7AE5D\%7D; 2013.

[94] Kryzhanovski V, Morgan R, Sponseller CA, Davidson MH. Pitavastatin $4 \mathrm{mg}$ provides significantly greater reduction in LDL-C compared to pravastatin $40 \mathrm{mg}$ with neutral effects on glucose metabolism: prespecified safety analysis from the short-term phase 4 PREVAIL US trial in patients with primary hyperlipidemia or mixed dyslipidemia. J Am Coll Cardiol 2012;59:E1692.

[95] Kryzhanovski V, Eriksson M, Hounslow N, Sponseller CA. Shortterm and long-term effects of pitavastatin and simvastatin on fasting plasma glucose in patients with primary hyperlipidemia or mixed dyslipidemia and $>=2$ risk factors for CHD. J Am Coll Cardiol 2012;59:E1659.

[96] Danaei G, Garcia Rodriguez LA, Fernandez CO, et al. Statins and risk of diabetes: an analysis of electronic medical records to evaluate possible bias due to differential survival. Diabetes Care 2013; 36:1236-40.

[97] Supale S, Li N, Brun T, et al. Mitochondrial dysfunction in pancreatic beta cells. Trends Endocrinol Metab 2012;23:477-87.

[98] Sampson UK, Linton MF, Fazio S. Are statins diabetogenic? Curr Opin Cardiol 2011;26:342-7.

[99] Koh KK, Sakuma I, Quon MJ. Differential metabolic effects of distinct statins. Atherosclerosis 2011;215:1-8.

[100] Hoeks J, Schrauwen P. Muscle mitochondria and insulin resistance: a human perspective. Trends Endocrinol Metab 2012;23: 444-50.

[101] Kusminski CM, Scherer PE. Mitochondrial dysfunction in white adipose tissue. Trends Endocrinol Metab 2012;23:435-43.

[102] Rosenbaum D, Dallongeville J, Sabouret P, et al. Discontinuation of statin therapy due to muscular side effects: a survey in real life. Nutr Metab Cardiovasc Dis 2012;23:871-5.

[103] Draeger A, Monastyrskaya K, Mohaupt M, et al. Statin therapy induces ultrastructural damage in skeletal muscle in patients without myalgia. J Pathol 2006;210:94-102.

[104] Golomb BA, Evans MA, Dimsdale JE, et al. Effects of statins on energy and fatigue with exertion: results from a randomized controlled trial. Arch Intern Med 2012;172:1180-2.

[105] Liao JK. Safety and efficacy of statins in Asians. Am J Cardiol 2007;99:410-4.

[106] Culver AL, Ockene IS, Balasubramanian R, et al. Statin use and risk of diabetes mellitus in postmenopausal women in the Women's Health Initiative. Arch Intern Med 2012;172:144-52.

[107] Krumholz HM, Vaccarino V, Mendes de Leon CF, et al. Cholesterol and coronary heart disease mortality in elderly patients. J Am Med Assoc 1996;275:110-1.

[108] Foody JM, Rathore SS, Galusha D, et al. Hydroxymethylglutaryl$\mathrm{CoA}$ reductase inhibitors in older persons with acute myocardial infarction: evidence for an age-statin interaction. J Am Geriatr Soc 2006;54:421-30.

[109] Robinson JG, Booth B. Statin use and lipid levels in older adults: National Health and Nutrition Examination Survey, 2001 to 2006. J Clin Lipidol 2010;4:483-90.

[110] Zillich AJ, Garg J, Basu S, et al. Thiazide diuretics, potassium, and the development of diabetes: a quantitative review. Hypertension 2006;48:219-24.

[111] Alderman MH. New onset diabetes during antihypertensive therapy. Am J Hypertens 2008;21:493-9. 